\title{
Role of Magnetic Resonance Imaging in Diagnosis of Pelvic Floor Dysfunction in Female Patients
}

\author{
M.M.Refaat ${ }^{1}$, G.E.Saleh ${ }^{2}$, R.F.Elsayed ${ }^{3}$, M.I.Yousef ${ }^{1}$ and T.A.Sharaf Eldean ${ }^{1}$ \\ ${ }^{1}$ Radiodiagnosis, Dept., Faculty of Medicine, Benha Univ., Benha, Egypt \\ ${ }^{2}$ General Surgery, Dept., Faculty of Medicine, Benha Univ., Benha, Egypt \\ ${ }^{3}$ Radiodiagnosis, Dept., Faculty of Medicine, Cairo Univ., Cairo, Egypt \\ E-mail:Tamer2539801@yahoo.com
}

\begin{abstract}
Peri- and post-menopausal women are at an increased risk of pelvic floor dysfunction (PFD). As a term for a wide range of medical conditions, it may refer to everything from incontinence and abnormalities to prolapse and sexual dysfunction. When used for morpho-functional evaluation, MRI may be a valuable asset. An important goal of this new, forward-looking study was to compare dynamic and static magnetic resonance imaging (MRI) in evaluating female pelvic floor diseases and identify any commonalities. Study Subjects and Procedures: Clinical and dynamic/static magnetic resonance imaging tests were performed on 65 women in total ( 55 cases and 10 controls). Those in the patient population who have symptoms such as chronic constipation, obstructed bowels, prolapsed pelvic floor, stress incontinence, or anal incontinence should be referred. Static and dynamic MRI were used on all of the participants. Overall, the mean patient age was 39 years (SD: 14 years). Concerning the relationship between static and dynamic testing, muscle and fascial defects were shown to be the most common defect in people with constipation, pelvic organ prolapse, and stress urine incontinence. Anal incontinence was associated with anal sphincter complex impairment. As a result, structural and functional changes may be identified using static and dynamic MRI, making it an important tool in the evaluation of female patients with PMS.
\end{abstract}

Key Words: Pelvic floor dysfunction, Static/Dynamic Magnetic Resonance imaging, evacuation phase, Female.

\section{Introduction}

Pelvic floor dysfunction (PFD) is a prevalent health problem among women nowadays [1] a bony structure that supports the pelvic organs and controls the anal sphincters and urethra at rest and voluntarily. Women have a considerably higher level than males [2]. Disorders such as incontinence, prolapse of the lower urinary tract, disruptions of the defecation process, and sexual activity may all be referred to by the acronym (PFD). [3]. Variables that contribute to high intraabdominal pressure include old age, obesity, pregnancy, multiple births, menopause, connective tissue disorders, smoking, and any other condition that elevates it.... [4]

This connective tissue and muscle network helps to support the pelvic floor. Closing the urogenital hiatus is aided by levator ani muscle lift. There are three muscles in this group: the iliococcygeus, pubococcygeus, and puborectalis. An example of supporting connective tissue is that which surrounds the vagina and the perineal body, as well as the arcus tensor levator ani. Denervation of the muscles may weaken the pelvic floor by putting stress on the fascia.

In order to fully evaluate the affected structures, clinical evaluations, physiologic testing, and counselling about conservative therapy versus surgical options are often required [7]. In clinical assessment, defecography is often beneficial. Static/dynamism imaging technique, which enables imaging of all pelvic floor compartments, is an useful tool for detecting complex pelvic floor diseases.

Pelvic diseases may manifest as a single compartment illness or as weakness or dysfunction of the whole pelvic floor, thus a combination of static and dynamic findings is needed. Pelvic floor disorders can only be accurately diagnosed by imaging, and dynamic MR defecography is a useful tool for this purpose[4]. As a result, the investigation's goal was to establish whether or not pelvic floor dysfunction (PFD) is caused by a specific pelvic floor disease by examining the use of MRI in diagnosing individuals with PFD, as well as static and dynamic imaging techniques.

\section{Patients and methods \\ 2.1. Patients' population}

The study was conducted on 65 women from April 2018 to December 2020. Ten volunteer women served as a control group, and 55 women served as patient group. All patients were referred from the surgery clinic, Benha Faculty of Medicine for MRI evaluation; all participants were evaluated by clinical history and examination at the surgery department. Informed consent was obtained from the control group and all patients who fulfill the inclusion criteria.

\subsection{Inclusion criteria}

Any patient with manifestations of pelvic floor dysfunction. They were categorized according to their chief symptoms into five groups as follow:

- Chronic constipation.

- Obstructed defecation (OD).

- Pelvic organ prolapse (POP).

- Stress urinary incontinence (SUI).

- Anal incontinence (AI).

\subsection{Exclusion criteria}

- The use of electronic (e.g., cardiac pacemakers) and metallic implants (e.g., cardiac valves or piercings). 
- Currently under treatment for malignancy.

- Claustrophobia.

- Pregnancy.

- Previous radiation to the pelvis.

- Pelvic masses.

- Anorectal malformation.

- If they had any cognitive problems affected their ability to cooperate and give informed consent.

\subsection{Patient Preparation}

According to advice of the ESUR and ESGAR, [10], the following should be fulfilled:

- A full patients' history was taken.

- All patients underwent cleaning rectal enema the night before MR imaging.

- No need to contrast agents orally or intravenously.

- The urinary bladder is moderately filled, voiding urine two hours before the examination.

- The evacuation phase is important because POP is only evident when abdominal pressure increases.

\subsection{MRI technique}

- Images were obtained using 1.5-T MR imaging unit (Siemens healthineers Global- MAGNETOM Sempra 1.5 Tesla) using a pelvic phased-array coil.

- Ultrasound gel (90 to $120 \mathrm{~mL}$ ) was placed into the rectum.

- The patients were examined in the supine position with the knees elevated because to facilitate straining and evacuation.

- A pad was placed under the patient to add comfort when evacuating the rectum and to avoid contamination of the MR table.

\subsection{MRI analysis}

We followed Elsayed et al. [10] method for MR protocol, as follows:

\subsection{Static MR imaging sequences:}

High-resolution T2- weighted images (T2WI) (in three planes (axial, coronal, sagittal) (repetition time ms/echo time ms (TR/TE) 5000/132, field of view (FOV) 240-260 mm, slice thickness 2-4 mm, gap 0-0.5 $\mathrm{mm}$, number of signals acquired 2, flip angle 90, matrix $512 \times 512$, acquisition time $3.12 \mathrm{~min}$ for each sequence]

\subsection{Dynamic (kinematic) MR imaging sequences:}

Acquisition of five sections during the phases (a) at rest. b) During squeezing and c) During maximum straining, in the three planes (axial, coronal, sagittal) using true fast imaging with steady-state free precession (TRUFI) (TR/TE 5.0/1.6 ms, FOV $300 \mathrm{~mm}$, slice thickness 5-7 mm, gap0.0- $0.7 \mathrm{~mm}$ ).

\subsection{Evacuation phase}

The images were obtained in the sagittal plane with the similar parameters of the previously mentioned dynamic sagittal dynamic protocol. The evacuation sequence was considered adequate when the injected gel is seen passing through the anal canal lumen. It was repeated until the rectum is totally emptied to exclude rectal intussusceptions.

\subsection{Image analysis}

We followed the instructions of Elsayed [11] on analytical approach of the static and dynamic imaging as well as correlation of both studies. Regarding the static images, the urethral supporting structures consist of ligaments, level III fascial support and the puborectalis muscle. The assessment of the vaginal supporting structures including the level I \&II fascia, and the iliococcygeus muscle. Finally, evaluation of the anal sphincter lesions were classified according to the muscle injured (the internal or external anal sphincter).

In the analysis of dynamic imaging, the pubococcygeal line (PCL) obtained by a line drown from the inferior border of the symphysis pubis anteriorly to the tip of the coccyx posteriorly, was used as the reference line. For each participant, the descent of the bladder neck, bladder base, uterus, and anorectal junction below the PCL was recorded. Other measurements in the sagittal plane during maximum straining included the levator plate angle, which is enclosed between the levator plate and the PCL was measured in maximum straining. In the axial and coronal planes, respectively, the width of the levator hiatus and the iliococcygeus angle were measured during maximum straining. These measurements were all considered to reflect the status and the weakness of the levator ani.

\subsection{Statistical analysis}

Data were collected, coded, and entered to Statistical analysis were performed using IBM SPSS Statistics version 25 (IBM, Armonk, New York, United States). Quantitative data were summarized as means (M) and standard deviations (SD) and compared using independent t-test for two groups comparisons or one-way ANOVA for more than two groups' comparisons followed by Dunnett's test as a post hoc analysis to judge the difference among values of individual parameters. Categorical data were summarized as numbers and percentages. It were compared using the Chi square or Fisher's exact test. P-value of $<0.05$ was considered statistically significant for all tests.

\section{Results}

A total of 65 women were included in the study, dynamic/static pelvic floor MRI was successfully completed in 55 patients with a mean age of $39( \pm$ SD $=$ 14 years) and ten women served as control with mean age of $36( \pm \mathrm{SD}=3$ years $)$. There was a non-significant difference between both groups; $(\mathrm{P}$ value $=0.096)$.

In healthy control, continent women, even with maximal downward pelvic strain, MR images demonstrate minimal descent of the pelvic organs. The bladder neck, vaginal fornixes, and anorectal junction all stay at or above the pubococcygeal line. On sagittal images obtained during pelvic strain, the urethra should maintain its normal, slightly anterior orientation to the 
bladder base. On axial images, the entirety of the levator sling should be of similar thickness and homogeneous low signal intensity. On coronal images, the iliococcygeal muscle should be intact and upwardly convex. As women age, some thinning of the levator ani muscle occurs normally; however, no tears should be identified. The vagina should have an $\mathrm{H}$-shaped configuration, which indicates adequate lateral fascial support Fig. (1)

\section{Chief symptoms}

The most frequent symptom was obstructed defecation $(38.2 \%)$, followed by constipation $(25.5 \%)$, pelvic organ prolapse $(16.4 \%)$, anal incontinence $(10.9 \%)$, and stress urinary incontinence $(9.1 \%)$ Fig. (2)

\section{Analysis of the Static Study and Assessment of the Supporting Structures:}

Regarding vaginal supporting structures, Level I \& II endopelvic fascia defect was significantly higher in cases $(47.3 \%)$ compared to controls $(0.0 \%)$; P-value was 0.005. Also, iliococcygeus muscle defect was significantly higher in cases $(20.0 \%)$ than controls $(0.0 \%)$; P-value was 0.121 . There were a significant difference in puborectalis muscle defect and level III endopelvic fascia defect incases as compared to control groups; P-values were 0.047 and 0.034 , respectively. As regards to anal sphincter, there were non-significant differences in external or internal anal sphincter defects; P-values were 0.072 and 1 , respectively Fig. $(3,4)$.

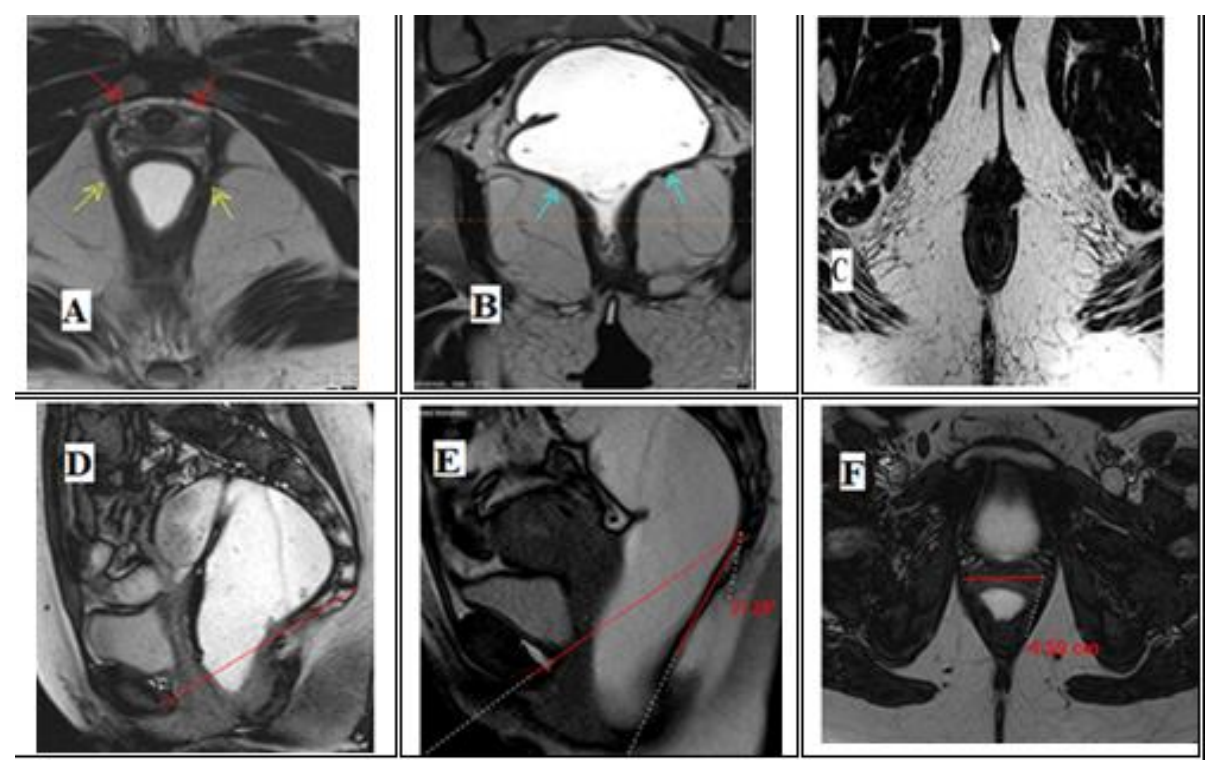

Fig. (1) Normal static/dynamic MR imaging findings in 22-year-old woman in control group. A\& B: axial and coronal T2-weighted turbo spin-echo (TSE). Static images showing normal pelvic floor muscles (Yellow arrows: puborectalis, blue arrows: Iliococcygeus and Red arrows: level III endopelvic fascia). C: Static axial T2-weighted (TSE) images at the level of anal canal showing normal anal sphincter complex. D: Dynamic sagittal true fast imaging with steady-state free precession (TRUFI) image during evacuation phase showing no pelvic organ descent below the PCL (Red line) and

no anterior rectocele. (E, F\&G): Dynamic images (TRUFI) in three orthogonal planes during maximum straining showing normal supportive measurements. E: The sagittal plane: the levator plate angle (LPA)measuring 27.2o. F: Axial plane: width of the levator hiatus (WLH) measured $4.6 \mathrm{~cm}$. G: Coronal plane: The iliococcygeus angle (ILCa) measured 54.90

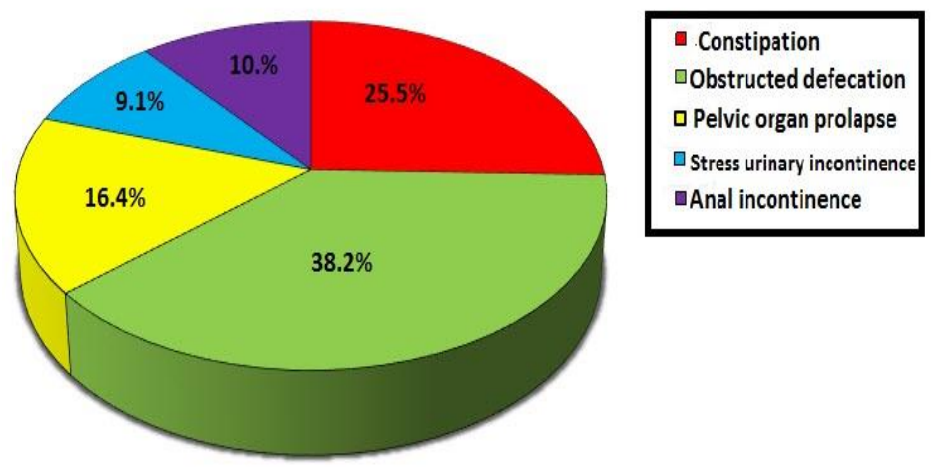

Fig. (2) Classification of the patient groups according to chief symptoms 


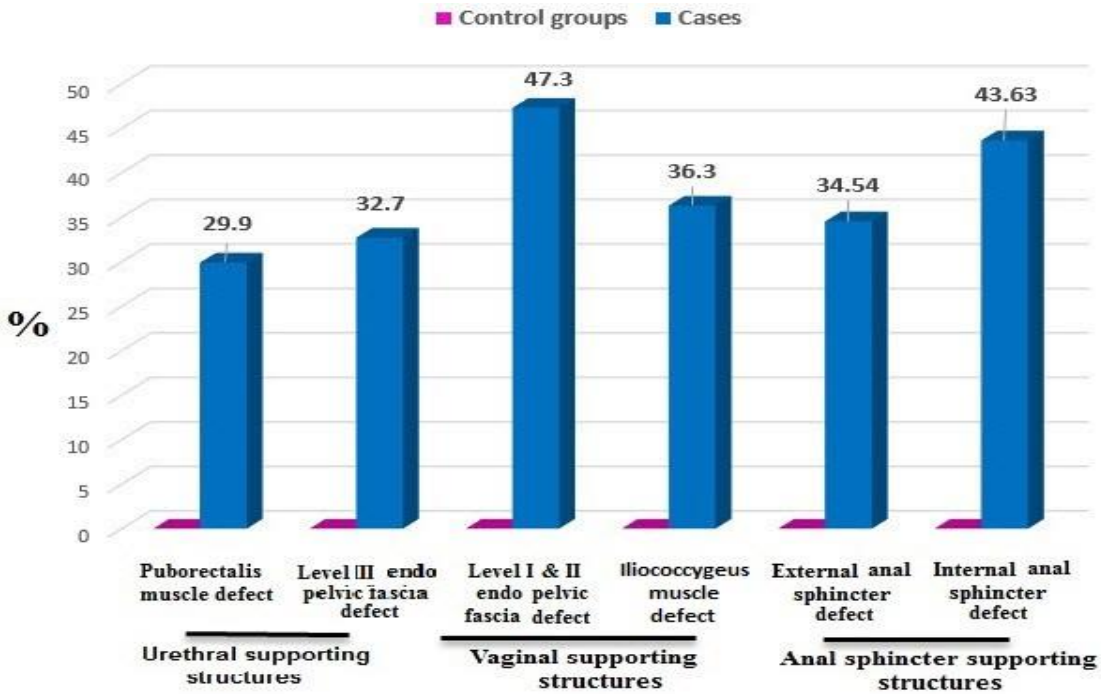

Fig. (3) Supporting structures obtained in both groups

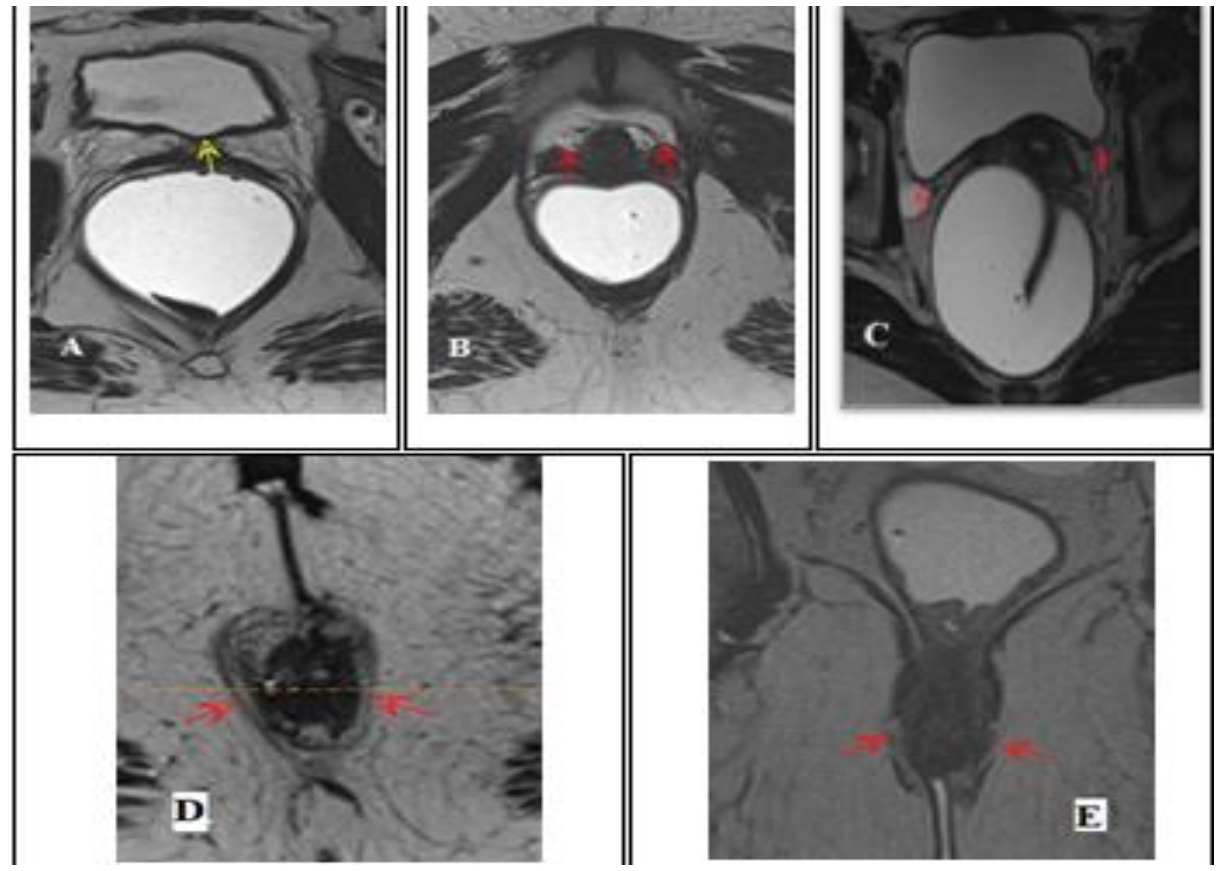

Fig. (4) Static T2WIs (TSE) images in different patients. (A) axial images showing level II central endopelvic fascial defect (Yellow arrow). (B) axial images showing bilateral level III endopelvic fascia defect supporting proximal urethra (Red arrows). (C) axial images Showing bilateral level I / II endopelvic fascia paravaginal defect. (D\&E): axial and coronal images of the anal canal showing atrophy of the lower $1 / 3$ of the deep external anal sphincter with marked thinning of the muscle bulk (Red arrows).

\section{Frequency of Pelvic Supporting Structures Defects} in Each Patient sub-Group (table 1):

- In the constipation group (14 cases), 4 patients $(28.6 \%)$ showed external anal sphincter defect and only one patient $(7.1 \%)$ showed internal anal sphincter defect. Regarding the vaginal supporting structures, 8 out of 14 (57.1\%) showed level I / II endopelvic fascia defect and only 3 patients $(21.4 \%)$ showed iliococcygeus muscle defect. in respect of the urethral supporting structures only 2 patients (14.3\%) showed level III endoplevic fascia defect.
- In obstructed defecation group (21 cases), there was 5 out of 21 patient $(23.8 \%)$ showed external anal sphincter defect and only 2 patients $(9.5 \%)$ showed internal anal sphincter defect. Regarding the vaginal supporting structures, 6 patients (28.6\%) showed level I / II endo-pelvic fascia defect and 5 out of $21 \quad(23.8 \%)$ showed iliococcygeus muscle defect. Finally, for urethral $\begin{array}{llll}\text { supporting } & \text { structures } 7 & (33.3 \%) & \text { showed }\end{array}$ puborectalis muscle defect and only $3(14.3 \%)$ showed level III endopelvic fascia defects.

- In the pelvic organ prolapse group (9 cases),6 patients $(66.7 \%)$ showed level I/II endopelvic 
fascia defect and 2 patients showed iliococcygeus muscle defect (22.2\%). While, as regarding urethral structures, 4 patients $(44.0 \%)$ showed level III endopelvic fascia defect and only 2 patients showed puborectalis muscle defect. Only one patient showed external anal sphincter defect and another one showed internal anal sphincter defect.

- In stress urinary incontinence group (5 cases), all patients showed level III endopelvic fascia and one out of 5 patients (20\%) showed puborectalis muscle defect. While as regarding the vaginal supporting structures, 4 patients $(80.0 \%)$ showed level I \& II endopelvic fascia and one (20\%) The most frequent abnormalities in the patient group:

Ano-rectal junction descent was the most frequent abnormality $(83.6 \%)$, followed by anterior rectocele showed Iliococcygeus muscle defect. In assessment of the anal sphincter complex, one patient $(20 \%)$ showed external anal sphincter defect and no abnormality detected regarding the internal anal sphincter defect.

- In the anal incontinence group (6 cases),3 patients $(50.0 \%)$ showed external anal sphincter defect and one patient $(16.7 \%)$ showed internal anal sphincter defect. Regarding the vaginal supporting structures, two patients (33.3\%) showed level I / II endopelvic fascial defect. In assessment of the urethral supporting structures Only one (16.7\%) showed level III endopelvic fascia defect.

Analysis of the Evacuation Phase:

$(70.9 \%)$, cystocele $(65.5 \%)$, and uterine descent (45.5\%). (Fig.5, 7 B, D).

Table (1) Frequency of the defects detected in the supporting structures defects in each patient subgroup.

\begin{tabular}{|c|c|c|c|c|c|c|c|c|c|c|c|}
\hline & & & & & pated & ient & & & & & \\
\hline & $\begin{array}{l}\text { supporting } \\
\text { es }\end{array}$ & & & & l supp & ing & Icture & An & hincte & & \\
\hline & $\begin{array}{l}\text { I } \\
\text { vic fascia }\end{array}$ & & cygeus & & ctalis & & $\begin{array}{r}\text { III } \\
\text { pelvic }\end{array}$ & $\mathbf{E x}$ & & Int & nal \\
\hline $\mathrm{N}$ & $\%$ & $\mathrm{~N}$ & $\%$ & $\mathrm{~N}$ & $\%$ & $\mathrm{~N}$ & $\%$ & $\mathrm{~N}$ & $\%$ & $\mathrm{~N}$ & $\%$ \\
\hline 8 & 57.1 & 3 & 21.4 & 0 & 0.0 & 2 & 14.3 & 4 & 28.6 & 1 & 7.1 \\
\hline & ted defeca & ion & & & & & & & & & \\
\hline $\mathrm{N}$ & $\%$ & $\mathrm{~N}$ & $\%$ & $\mathrm{~N}$ & $\%$ & $\mathrm{~N}$ & $\%$ & $\mathrm{~N}$ & $\%$ & $\mathrm{~N}$ & $\%$ \\
\hline 5 & 28.6 & 5 & 23.8 & 7 & 33.3 & 3 & 14.3 & 5 & 23.8 & 2 & 9.5 \\
\hline & rgan prola & & & & & & & & & & \\
\hline $\mathrm{N}$ & $\%$ & $\mathrm{~N}$ & $\%$ & $\mathrm{~N}$ & $\%$ & $\mathrm{~N}$ & $\%$ & $\mathrm{~N}$ & $\%$ & $\mathrm{~N}$ & $\%$ \\
\hline 6 & 66.7 & 2 & 22.2 & 2 & 22.2 & 4 & 44.4 & 1 & 11.1 & 1 & 11.1 \\
\hline & rinary inco & ntin & & & & & & & & & \\
\hline $\mathrm{N}$ & $\%$ & $\mathrm{~N}$ & $\%$ & $\mathrm{~N}$ & $\%$ & $\mathrm{~N}$ & $\%$ & $\mathrm{~N}$ & $\%$ & $\mathrm{~N}$ & $\%$ \\
\hline 4 & 80.0 & 1 & 20.0 & 1 & 20.0 & 5 & 100.0 & 1 & 20.0 & 0 & 0.0 \\
\hline & ontinence & & & & & & & & & & \\
\hline $\mathrm{N}$ & $\%$ & $\mathrm{~N}$ & $\%$ & $\mathrm{~N}$ & $\%$ & $\mathrm{~N}$ & $\%$ & $\mathrm{~N}$ & $\%$ & $\mathrm{~N}$ & $\%$ \\
\hline 2 & 33.3 & 0 & 0.0 & 0 & 0.0 & 1 & 16.7 & 3 & 50.0 & 1 & 16.7 \\
\hline
\end{tabular}

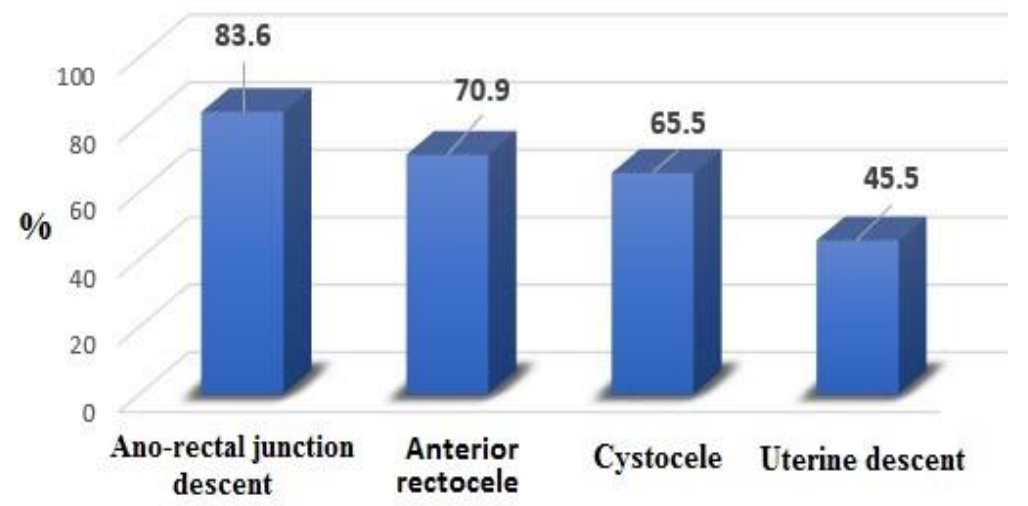

Fig. (5) Frequency of abnormalities detected in evacuation phase in dynamic study patient group 
Functional abnormalities detected in evacuation phase:

The most frequent abnormality was spastic anal sphincter (Fig $6 \mathrm{D}$ ), detected in 21 out of 55 patient $(38.2 \%)$, followed by intussusception (Fig. $6 \mathrm{E}$ ), reported in 18 out of 55 patient $(32.7 \%)$, spastic puborectalis Fig (6C) by 6 out of $55(10.9 \%)$ as well as dilated rectosigmoid and urine loss during maximum straining Fig (6A) detected in 2 patients $(3.6 \%)$.

Evacuation phase findings in each patient subgroups Table (2)

- In the constipation group, (78.6\%) of patients showed urinary bladder descent, with a mean of $2.1 \mathrm{~cm} .50 \%$ showed genital descent, with a mean of $2 \mathrm{~cm}$. Anterior rectocele $(92.9 \%)$, with a mean of $3.5 \mathrm{~cm}$. All patients showed anorectal junction descent, with a mean of $7 \mathrm{~cm}$.

- In obstructed defecation group,( 52.4\%) showed urinary bladder descent, with a mean of $2.2 \mathrm{~cm}$,
(38.1\%) showed genital descent, with a mean of 2 $\mathrm{cm}$. (71.4\%) showed anterior rectocele, with a mean of $3.1 \mathrm{~cm}$. Most patients $(85.7 \%)$ showed anorectal junction descent, with a mean of $6.4 \mathrm{~cm}$.

- In the pelvic organ prolapse group, all patients showed urinary bladder descent, with a mean of $2.6 \mathrm{~cm}$., (77.8\%) showed genital descent, with a mean of $3.4 \mathrm{~cm}$. Most patients $(88.9 \%)$ showed anterior rectocele, with a mean of $3.4 \mathrm{~cm}$. All patients showed anorectal junction descent, with a mean of $8 \mathrm{~cm}$.

- In the stress urinary incontinence group, all patients showed urinary bladder descent, with a mean of $3.4 \mathrm{~cm}$., (60\%) showed genital descent, with a mean of $1.7 \mathrm{~cm}$., $(60.0 \%)$ showed anterior rectocele, with a mean of $3.3 \mathrm{~cm}$. All patients showed anorectal junction descent, with a mean of $5.6 \mathrm{~cm}$.
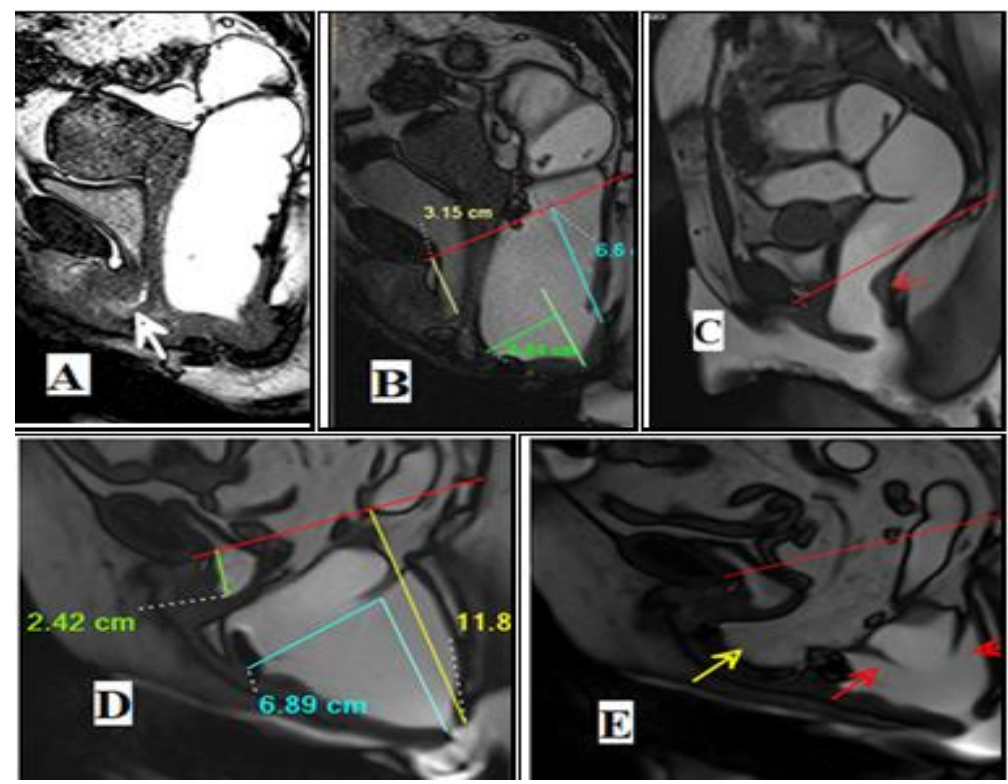

Fig. (6) Dynamic (TRUFI) Sagittal images during evacuation phase in different patients: (A) showed loss of urine during early evacuation phase (White arrow) (B) showed $3.1 \mathrm{~cm}$ UB base descent below the PCL (yellow line) and 6.6 $\mathrm{cm}$ descent of the ARJ (blue line) as well as $3.84 \mathrm{~cm}$ anterior rectocele (green line) with associated diminished anal canal lumen suggestive of spastic anal sphincter. (C) Spastic contraction puborectalis (Red arrow). (D) The red line representing the PCL, UB base descent for $2.4 \mathrm{~cm}$ (Green line), and $11.96 \mathrm{~cm}$ descent of the ARJ (yellow line) as well as anterior rectocele measuring $6.89 \mathrm{~cm}$ (Blue line) with associated spastic anal sphincter. (E) showing large peritoniocele and enterocele (Yellow arrow) and low recto-rectal intussusception (Red arrows).

Table (2) Evacuation phase findings in each patient subgroup

\begin{tabular}{lcccc}
\hline & & \multicolumn{3}{c}{ Pelvic organ descent } \\
& Urinary bladder & Genital & Ant rec & Anorectal junction \\
& $\mathbf{N}(\%)$ & $\mathbf{N}(\%)$ & $\mathbf{N}(\%)$ & $\mathbf{N}(\%)$ \\
\hline Constipation & $11(78.6)$ & $7(50.0)$ & $13(92.9)$ & $14(100.0)$ \\
Obstructed defecation & $11(52.4)$ & $8(38.1)$ & $15(71.4)$ & $18(85.7)$ \\
Pelvic organ prolapse & $9(100.0)$ & $7(77.8)$ & $8(88.9)$ & $9(100.0)$ \\
Stress urinary incontinence & $5(100.0)$ & $3(60.0)$ & $3(60.0)$ & $5(100.0)$ \\
\hline
\end{tabular}

Analysis of the Dynamic Imaging During Maximum Straining in Three Orthogonal Planes:

Comparison between the supportive measurements in patient group Vs control group Table (5)

Levator plate angle, the width of levator hiatus and Iliococcygeal angle were significantly $(\mathrm{P}<0.001)$ higher in cases compared to the control group. 
Table (3) Measurements obtained at the dynamic study in both groups.

\begin{tabular}{lccc}
\hline & Controls $(\mathbf{N}=10)$ & Cases $(\mathbf{N}=\mathbf{5 5})$ & P-value \\
\hline Levator Plate angle $\mathbf{(}^{\mathbf{0}}$ ) & $27.2 \pm 1.4$ & $49.1 \pm 17.2$ & $\mathrm{P}<0.001$ \\
Width of Levator hiatus $(\mathbf{c m})$ & $4.8 \pm 0.3$ & $5.9 \pm 1.3$ & $\mathrm{P}<0.001$ \\
$\quad$ Iliococcygeal angle $\left(^{\mathbf{0}}\right)$ & $36.8 \pm 2.7$ & $53.7 \pm 14.4$ & $\mathrm{P}<$ \\
& & & 0.001 \\
\hline
\end{tabular}

Data are expressed as Mean \pm SD

The level of significance is set at $\mathrm{P}<0.05$

Independent t-test was used.

Comparison Between the Supportive Measurements

in Each Patient Subgroup Vs Control Group:

- Levator plate angle showed an overall significant difference between groups. There was significantly increase in the constipation group (53.8o), obstructed defecation group (49.4o), and pelvic organ prolapse $(58.7 \mathrm{o})$ compared to the control group (27.20) (Fig 7-A).

- The width of the levator hiatus showed an overall significant difference between groups. It was significantly higher in the constipation group (5.8 $\mathrm{cm})$, obstructed defecation group $(5.9 \mathrm{~cm})$, and pelvic organ prolapse $(7.4 \mathrm{~cm})$ compared to the control group (4.8 cm) (Fig 7-B).

- Iliococygeal angle showed an overall significant difference between groups (P-value $<0.001)$. The angle was significantly higher in the constipation group (56o), obstructed defecation group (52.4o), and pelvic organ prolapse $(65.7 \mathrm{o})$ compared to the control group (36.8o) (Fig 7-C).

Table (4) Measurements obtained in Dynamic study in patient and control groups

\begin{tabular}{lccc}
\hline & Levator Plate Angle $\left(^{\mathbf{0}}\right)$ & Width of levator Hiatus $(\mathbf{c m})$ & Iliococcygeal Angle $\left({ }^{\mathbf{0}}\right)$ \\
\hline Constipation & $53.8 \pm 10.4 *$ & $5.8 \pm 0.8 *$ & $56 \pm 11 *$ \\
Obstructed defecation & $49.4 \pm 18.9 *$ & $5.9 \pm 1.3 *$ & $52.4 \pm 14.9 *$ \\
Pelvic organ prolapse & $58.7 \pm 16.5 *$ & $7.4 \pm 1.2 *$ & $65.7 \pm 10.2 *$ \\
Stress urinary incontinence & $45.4 \pm 12.4$ & $5.1 \pm 1.7$ & $52.2 \pm 15.5$ \\
Anal incontinence & $25.4 \pm 3$ & $4.6 \pm 0.5$ & $36 \pm 3.6$ \\
Control & $27.2 \pm 1.4$ & $4.8 \pm 0.3$ & $36.8 \pm 2.7$ \\
P-value & $<0.001$ & $<0.001$ & $<0.001$ \\
\hline
\end{tabular}

Data presented as mean \pm SD

One-way ANOVA test was used

* Significant difference compared to the control group.
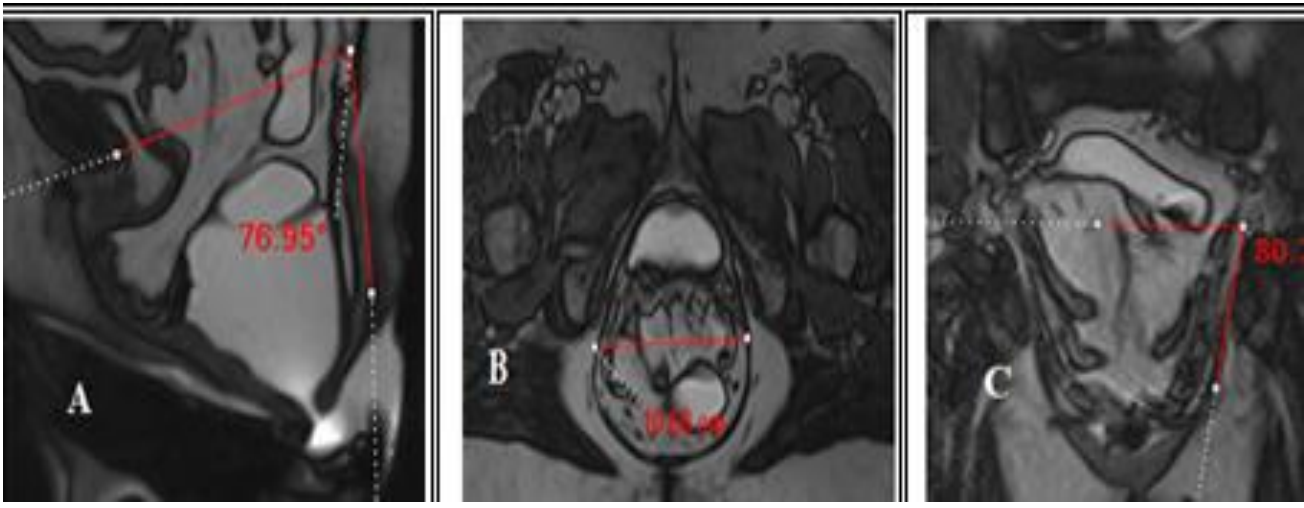

Fig (7) Dynamic images (TRUFI) in three orthogonal planes during maximum straining in patient with pelvic organ prolapse (a)Sagittal plane LPA measuring 76.950.(B)Axial plane WLH measuring $10.6 \mathrm{~cm}$. (C)Coronal plane ILCa measured 80.760 .

Correlation of Static and Dynamic Studies and Discrimination of the Underlying Predominant Defect Table (5)

- In obstructed defecation subgroup, 17 out of 21 patients $(81.0 \%)$ showed pelvic floor muscle weakness.

- In the constipation subgroup, 8 out of 14 patients (57.1\%) showed combined pelvic floor muscle weakness and endopelvic fascial defects.
- In the anal incontinence subgroup, 4 out of 6 patients $(66.7 \%)$ showed anal sphincter complex defect.

- In the pelvic organ prolapse subgroup,7 out of 9 patients showed combined pelvic floor muscle weakness and endoplevic fascial defects.

- In stress urinary incontinence subgroup, 3 out of 5 patients $(60.0 \%)$ showed endopelvic fascial defects. 
Table (5) the most predominant defect regarding the correlation between the static and dynamic studies.

\begin{tabular}{lcccccccccc}
\hline & \multicolumn{2}{c}{$\begin{array}{c}\text { Muscle } \\
\text { defect }\end{array}$} & \multicolumn{2}{c}{$\begin{array}{c}\text { Fascial } \\
\text { defect }\end{array}$} & \multicolumn{2}{c}{$\begin{array}{c}\text { Muscle \& fascial } \\
\text { defect }\end{array}$} & \multicolumn{2}{c}{$\begin{array}{c}\text { Anal sphincter } \\
\text { complex }\end{array}$} & \multicolumn{2}{c}{$\begin{array}{c}\text { Retention with } \\
\text { overflow }\end{array}$} \\
& $\mathrm{N}$ & $\%$ & $\mathrm{~N}$ & $\%$ & $\mathrm{~N}$ & $\%$ & $\mathrm{~N}$ & $\%$ & $\mathrm{~N}$ & $\%$ \\
\hline $\begin{array}{l}\text { Constipation } \\
\text { Obstructed }\end{array}$ & 6 & 42.9 & 0 & 0.0 & 8 & 57.1 & 0 & 0.0 & 0 & 0.0 \\
defecation & 17 & 81.0 & 0 & 0.0 & 4 & 19.0 & 0 & 0.0 & 0 & 0.0 \\
$\begin{array}{l}\text { Pelvic organ prolapse } \\
\text { Stress urinary }\end{array}$ & 2 & 22.2 & 0 & 0.0 & 7 & 77.8 & 0 & 0.0 & 0 & 0.0 \\
incontinence & 0 & 0.0 & 3 & 60.0 & 2 & 40.0 & 0 & 0.0 & 0 & 0.0 \\
Anal incontinence & 0 & 0.0 & 0 & 0.0 & 0 & 0.0 & 4 & 66.7 & 2 & 33.3 \\
\hline
\end{tabular}

Data were presented as number $(\mathrm{N})$ and percentage $(\%)$

\section{Discussion}

The use of MR imaging of the pelvic floor to diagnose diseases of the pelvic floor is approved. Functional and structural details may be provided by simple sequences. Static/dynamic magnetic resonance imaging has been shown to be valuable in detecting and pinpointing structural abnormalities in the pelvic floor, allowing doctors to treat patients accordingly. One-tenth of the female participants were healthy volunteers, while the other two-thirds had one or more of the following conditions: chronic constipation, blockage of urine, or anal incontinence. The "MR defecography" modification made during the evacuation phase was used if you are interested in MRI, like Elsayed et al. [10]. Increases in evacuation rates were seen in patients with defecation dysfunction who received 140-180 ml of intra-rectal gel instead of the usual $80 / 100 \mathrm{ml}$, according to the Elsayed et al. study [14]. This finding was based on Idris's research findings. The supporting urethral, vaginal, and anal sphincter systems were evaluated using static imaging in the control and patient groups [14].

There was a substantial difference between the patients' vagina and urethra supporting structures and the controls in all instances. The deficiencies of the anal sphincter, on the other hand, were found to be non-significant. There have been studies on structural anomalies associated with constipation, obstructed defecation, pelvic organ prolapse, stress urinary incontinence, and anal incontinence. Females with urine incontinence are more likely to suffer from faecal incontinence and prolapse, according to Uustal et al. This hypothesis has been corroborated by our results. According to Elsayed [11], faecal incontinence affects as many as $17 \%$ of POP patients. This is because those with more severe prolapse are also more prone to have the problem.

These new findings echo those of Darwish et al. [16], who evaluated 21 people with complaints of pelvic floor dysfunction and found that $33.3 \%$ developed cystoceles or rectoceles throughout the dynamic study's evacuation phase. About one-third of the patients had either enteroceles or spastic pelvic syndrome (14.28 percent ). Only one instance of the descending perineal syndrome was discovered. In their study group, Hussein et al. [17] found that $70 \%$ of patients with pelvic floor dysfunction had bladder base descent, $65 \%$ had an anterior rectocele, and $50 \%$ had genital prolapse.

Pelvic organ descent was common in all groups, according to the findings of this research. In Elshazly [18]'s research of 31 constipated female patients with OD symptoms who had cystocele, anorectal junction descent, or $90 \%$ anterior rectocele, there were no reordered cases of genital descent. The majority of the women with symptoms of obstructed defecation showed anorectal junction descent with a mean of 5.15 $\mathrm{cm}$ and $70 \%$ of the cases indicated an anterior rectocele, according to research conducted by [13]. An anterior rectocele's size (more than $3 \mathrm{~cm}$ ) is one indication for surgical therapy, according to Solopova et al. [19]. The presence and extent of the rectocele must be documented for diagnostic and surgical purposes, therefore we did so. According to Roos et al., the size and emptying processes of the rectocele may be reliably evaluated using magnetic resonance imaging (MR defecography). In contrast to our results, Healy et al. [21] reported that video proctography was superior to MRI for the evaluation of rectocele.

Defecatory dysfunction was shown to be multifactorial in our study, with the majority of patients reporting several results. According to Pescatori et al., all patients had at least two undetected OD-related diseases. A variety of rectum and pelvic floor abnormalities contribute to obstructed defecation, and treatment may be customised to address a variety of rectum and pelvic floor problems.

Azab et al. [24] looked at women with urinary incontinence, faecal incontinence, or pelvic organ prolapse. Cystocele was found in $82.5 \%$ of the women, rectocele was found in $72.5 \%$ of the women, and vaginal prolapse was found in $4 \%$ of the women (10 percent ). Elsyaed [11] found a link between stress urinary incontinence and symptoms of pelvic outlet obstruction and obstructed defecation. This was confirmed in our research as well.

During our study, we discovered functional issues using the evacuation phase method. Elshazly [18] found 18 intussusceptions (45 percent) and 7 dyskinetic puborectalis muscles (17 percent) in 40 constipated individuals with OD symptoms. 
Fielding's (25] and Colaiacomo et al[26] .'s findings that an abnormal caudal inclination of the LPA at maximum strain is considered unhealthy and indicative of muscle weakness are supported by the results of our research. If we compare the Iliococcygeus angle to prior studies [25\&27], we find that it is statistically significant in identifying a sagging pelvic floor, which is in agreement with Elsayed [14].

According to Elsayed et al. [14], 6 out of 8 cases with anal incontinence showed anal sphincter injury when determining the primary defect via correlation between dynamic/static examinations in different groups. Our findings are in line with theirs. Endoanal MRI was conducted on six females with AI, and all of them had $100 \%$ anal sphincter impairment, according to Bharucha et al. [28]. There were anomalies in more than one pelvic compartment among the patients in our study, independent of the main symptoms of the current illness. It's possible that any or all of the pelvic visceral organs may be affected by pelvic floor dysfunction, according to Colaiacomo's results [26]. Because of this, dynamic MRI is becoming useful in detecting complex pelvic floor disorders by assessing the multi-compartmental involvement of pelvic dysfunction. So we agree with Elsayed [11], who said that anomalies in each compartment should be evaluated in connection to surrounding tissues and functional architecture of the pelvic floor. El. Elsayed Patients with SUI, POP, or anal incontinence may benefit from a combined study of static and dynamic MR imaging, as reported by Elsayed [11\&14]. This research provides additional information and allows the identification of structural abnormalities linked to specific pelvic floor dysfunction.

\section{Conclusion}

Since MR defecography can establish the entire pelvic floor when combined with static and dynamic sequences, it is a reliable alternative for noninvasive pelvic evaluation. This allows doctors to identify the primary problem and provide patients with the best possible care before surgical intervention.

Conflict of interest

Conflict of interest: The authors state that they have none.

\section{References}

[1] A.C. Pizzoferrato, K. Nyangoh Timoh, X. Fritel, E. Zareski, G. Bader, and A. Fauconnier, "Dynamic Magnetic Resonance Imaging and pelvic floor disorders: how and when?" European Journal of Obstetrics \& Gynecology and Reproductive Biology, vol. 181, pp. 259266, Oct. 2014, doi: 10.1016/j.ejogrb.2014.07.025.

[2] J. Lakhoo, G. Khatri, R. Elsayed, V. Chernyak, J. Olpin, A. Steiner, V. Tammisetti, K "MRI of the Male Pelvic Floor," RadioGraphics, vol. 39, pp. 2003-2022, Nov. 2019, doi: 10.1148/rg.2019190064.
[3] J. C. Salvador, M. P. Coutinho, J. M. Venâncio, and B. Viamonte, "Dynamic magnetic resonance imaging of the female pelvic floor - a pictorial review," Insights into Imaging, vol. 10, 2019.doi: 10.1186/s13244-019-0687-9.

[4] M.M. Corton, "Anatomy of Pelvic Floor Dysfunction," Obstetrics and Gynecology Clinics of North America, vol. 36, pp. 401-419, Sep. 2009, doi: 10.1016/j.ogc.2009.09.002.

[5] R.A. Word, S. Pathi, and J.I. Schaffer, "Pathophysiology of Pelvic Organ Prolapse," Obstetrics and Gynecology Clinics of North America, vol. 36, pp. 521-539, Sep. 2009, doi: 10.1016/j.ogc.2009.09.001.

[6] G.T. Bitti, M. Argiolas, N.Ballicu, E. Caddeo, M. Cecconi, G. Demurtas, G. Matta, M. T. Peltz, S. Secci, P.Siotto,, "Pelvic Floor Failure: MR Imaging Evaluation of Anatomic and Functional Abnormalities," RadioGraphics, vol. 34, pp. 429-448, Mar. 2014, doi: 10.1148/rg.342125050.

[7] V. Chernyak, J.Bleier, M.Kobi et al., "Clinical applications of pelvic floor imaging: opinion statement endorsed by the society of abdominal radiology (SAR), American Urological Association (AUA), and American Urogynecologic Society (AUGS)," Abdominal Radiology, vol. 46, pp. 1451-1464, Mar. 2021, doi: 10.1007/s00261-021-03017-8.

[8] K. Schawkat et al., "How to define pathologic pelvic floor descent in MR defecography during defecation?" Abdom Radiol, vol. 43, pp. 32333240, Jun. 2018, doi: 10.1007/s00261-0181652-7.

[9] R.F. El Sayed, D. Celine, M. Francesca, M. Matthias, M. Gabriele, M. Lucia, V. Valeria, W. Dominik, ESUR and ESGAR Pelvic Floor Working Group, "Magnetic resonance imaging of pelvic floor dysfunction - joint recommendations of the ESUR and ESGAR Pelvic Floor Working Group," Eur Radiol, vol. 27, 2017.doi: 10.1007/s00330-016-4471-7.

[10] R.F. El Sayed," Pelvic floor imaging" in Diagnostic imaging gynecol, 2nd edn Elsevier, Amirsys, 2015; pp 8/30-8/39.

[11] S. Gupta, J. B. Sharma, S. Hari, S. Kumar, K.K.Roy, and N. Singh, "Study of dynamic magnetic resonance imaging in diagnosis of pelvic organ prolapse," Arch. Gynecol. Obstet., vol. 286, pp. 953-958, 2012.doi: 10.1007/s00404-012-2381-8.

[12] T.A. Idris. The Role of MR Defecography in assessment of Anal incontinence, Obstructed Defecation and Simple Anal Diseases (Anal fissure, Hemorrhoids and Perianal Fistula). Master's thesis, Faculty of Medicine, Benha University, 2014.

[13] R.F. El Sayed, S.El Mashed, A. Farag, M. M. Morsy, and M.S. Abdel Azim, "Pelvic floor dysfunction: assessment with combined analysis 
of static and dynamic MR imaging findings," Radiology, vol. 248, 2008.doi: 10.1148/radiol.2482070974.

[14] E. Uustal Fornell, G. Wingren, and P. Kjølhede,, "Factors associated with pelvic floor dysfunction with emphasis on urinary and fecal incontinence and genital prolapse: an epidemiological study," Acta Obstet Gynecol Scand, vol. 83, 2004.doi: 10.1111/j.00016349.2004.00367. x.

[15] H. S. Darwish, H. A. Zaytoun, H. A. Kamel, and S. R. Qamar, "Assessment of pelvic floor dysfunctions using dynamic magnetic resonance imaging,” Egypt. J. Radiol. Nucl. Med., vol. 45, pp. 225-229, 2014.

[16] [17] N.A. Hussein, N.H. Shebrya, and N.N. Keriakos, "Role of dynamic MRI in assessment of pelvic floor dysfunction in females," Egypt. J. Hosp. Med., vol. 71, pp. 2742-2750, 2018.

[17] W.G. Elshazly, A.E.A. El Nekady, and H. Hassan, "Role of dynamic magnetic resonance imaging in management of obstructed defecation case series," Int. J. Surg., vol. 8, pp. 274-282, 2010.doi: 10.1016/j.ijsu.2010.02.008.

[18] A.E. Solopova, F.H.Hetzer, B. Marincek, and D. Weishaupt, "MR defecography: prospective comparison of two rectal enema compositions," AJR Am. J. Roentgenol., vol. 190, , pp. W11824, 2008.doi: 10.2214/AJR.07.2906

[19] J. E. Roos, D. Weishaupt, S. Wildermuth, J. K. Willmann, B. Marincek, and P. R. Hilfiker, "Experience of 4 years with open MR defecography: pictorial review of anorectal anatomy and disease," Radiographics, vol. 22, pp. 817-832, 2002.doi: 10.1148/radiographics.22.4. g02j102817.

[20] J. C. Healy, S. Halligan, R. H. Reznek, S. Watson, C. I. Bartram, R. Phillips, P. Armstrong, "Dynamic MR imaging compared with evacuation proctography when evaluating anorectal configuration and pelvic floor movement," AJR Am. J. Roentgenol., vol. 169, pp.

$775-779$, 1997.doi:10.2214/ajr.169.3.9275895.

[21] M. Pescatori, M. Spyrou, and A. Pulvirenti d'Urso, "A prospective evaluation of occult disorders in obstructed defecation using the 'iceberg diagram,"' Colorectal Dis., vol. 9, pp. 452-456, 2007.doi: 10.1111/j.14631318.2006.01094.x.

[22] A. Renzi, D. Izzo, G. Di Sarno, A. De Iuri, L. Bucci, G. Izzo, N. Di Martino, "Cinedefecographic findings in patients with obstructed defecation sindrome. A study in 420 cases," Minerva Chir., vol. 61, pp. 493-499, 2006.

[23] I.A. Azab, M.A. Nasef, and A.M. Ibrahim, "Dynamic magnetic resonance imaging: reliability of assessment and correlation with clinical findings of pelvic organ prolapse," The
Egyptian Journal of Radiology and Nuclear Medicine, vol. 45, 3, pp. 1003-1010, 2013.

[24] J.R. Fielding, "Practical MR imaging of female pelvic floor weakness," Radiographics, vol. 22, pp. 295-304, 2002.doi: 10.1148/radiographics.22.2.g02mr25295.

[25] M. C.Colaiacomo , G. Masselli, E. Polettini, S. Lanciotti, E. Casciani, L. Bertini, G. Gualdi, "Dynamic MR imaging of the pelvic floor: a pictorial review," Radiographics, vol. 29, , p. e35, 2009.doi: 10.1148/rg.e35.

[26] K. Singh, W.M.N. Reid, and L.A. Berger, "Magnetic resonance imaging of normal levator Ani anatomy and function," Obstet. Gynecol., vol. 99, pp. 433-438, 2002.doi: 10.1016/s00297844(01)01743-4.

[27] A.E. Bharucha, J.G. Fletcher, C.M. Harper, D. Hough, J.R. Daube, C. Stevens, B. Seide, S. J. Riederer, A. R. Zinsmeister, "Relationship between symptoms and disordered continence mechanisms in women with idiopathic faecal incontinence," Gut, vol. 54, pp. 546-555, 2005. 